\title{
Original
}

Article

\section{Optimal Culture Conditions for Constructing Durable Biografts for Repairing the Impaired Heart -Dynamic Cell Culture with Pre-seeding-}

\author{
Hiroki Yokomuro, MD, PhD, ${ }^{1}$ Noritsugu Shiono, MD, PhD, ${ }^{1}$ Yoshinori Watanabe, MD, PhD, ${ }^{1}$
}

Katsunori Yoshihara, $\mathrm{MD}, \mathrm{PhD},{ }^{1}$ Nobuya Koyama, $\mathrm{MD}, \mathrm{PhD},{ }^{1}$ and Mitsumasa Okada, $\mathrm{PhD}^{2}$

\begin{abstract}
Background: Tissue engineering with cell seeded biodegradable material has attracted attention as a novel means of treating the severely impaired heart. Here, we consider optimal preparation of a durable biograft using dynamic and static cultures.

Methods: Vascular smooth muscle cells (VSMCs) derived from the rat aorta were seeded onto biodegradable material $P(\mathrm{LA} / \mathrm{CL}$ ) (poly-L-lactide- $\varepsilon$-caprolactone copolymer) and cultured as follows: a) Static culture $(\mathrm{n}=11)$, b) dynamic culture $(\mathrm{n}=12)$, c) $0 \mathrm{~h}$ pre-seeding $(\mathrm{n}=12), \mathrm{d})$ $24 \mathrm{~h}$ pre-seeding $(\mathrm{n}=5)$ and e) 1 week pre-seeding $(\mathrm{n}=12)$. Dynamic culture: Cells were cultured in spinner flasks. Pre-seeding: Static cell seeding and culture before dynamic culture. Evaluation: The conditions of the $\mathrm{P}(\mathrm{LA} / \mathrm{CL})$ in the five groups were evaluated as cell proliferation and by histological studies.

Results: VSMCs proliferated both in and on the biodegradable materials. The quality of the dynamic culture cell with pre-seeding increased. Although the duration of pre-seeding exerted no significantly different effects, cell attachment and proliferation were widely scattered in the $0 \mathrm{~h}$ pre-seeding group, whereas cells proliferating on the front of the scaffold obstructed proliferation inside the biodegradable material in the 1 week pre-seeding group. Conclusions: Dynamic cell culture with $24 \mathrm{~h}$ pre-seeding is effective for constructing ideal biografts.
\end{abstract}

Keywords: dynamic cell culture, durable biograft, biodegradable material, pre-seeding technique

\section{Introduction}

Cell transplantation has been applied to treat ischemic cardiovascular diseases such as angina pectoris, myocar-

${ }^{1}$ Division of Cardiovascular Surgery, Department of Surgery, School of Medicine, Faculty of Medicine, Toho University, Tokyo, Japan

${ }^{2}$ Department of Biomolecular Science, Faculty of Science, Toho University, Funabashi, Chiba, Japan

Received: December 6, 2010; Accepted: January 24, 2011

Corresponding author: Hiroki Yokomuro, MD, PhD. Division of Cardiovascular Surgery, Department of Surgery, School of Medicine, Faculty of Medicine, Toho University, 6-11-1 Omorinishi, Ota-ku, Tokyo 143-8541, Japan

Email: h.yokomuro@chic.ocn.ne.jp

(C)2011 The Editorial Committee of Annals of Thoracic and Cardiovascular Surgery. All rights reserved. dial infarction, arteriosclerotic obliteration (ASO), Buerger's disease and other pathological conditions. ${ }^{1-4)}$ Tissue engineering is a more feasible therapy for the severely impaired heart than cell transplantation because it can prevent intercellular communication, release extra-cellular matrix (ECM), and persist longer at implantation sites. However, the conventional scaffold for tissue engineering has problems of poor or absent growth, no contractility, thrombogenicity and infection risk because it persists in the body. These difficulties can be overcome using a novel biodegradable material. Implanted autologous cells seeded on biodegradable materials have not yet caused immunological rejection.

Autologous bioengineered materials have only been clinically applied to the low pressure blood system of congenital heart disease. ${ }^{5)}$ However, a biograft suitable 
for a high pressure blood system in the clinical environment should be durable and easy to prepare.

A dynamic cell culture produces good effects on cell condition. Kim BS, et al. proposed that the stirred culture of smooth muscle cell (SMC)-seeded biodegradable polymer matrices increased a cell density, elastin and collagen synthesis rates, ${ }^{6}$ ) and the phenotype of the SMCs was strongly regulated by the scaffold chemistry. ${ }^{7}$ Williams $\mathrm{C}$, et al. tried to use a perfusion bioreactor for small diameter tissue-engineered arteries, and proposed that dynamic culture under pulsatile flow leads to cellular expression of differentiated function and extracellular matrix deposition toward the development of tissue-engineered arterial constructs. ${ }^{8)}$

We proposed that dynamic culture increased the proliferation of vascular smooth muscle cells (VSMCs) seeded on biodegradable materials. ${ }^{9)}$

The present study examines the notion that optimal dynamic culture conditions with pre-seeding would efficiently produce durable biografts.

\section{Materials and Methods}

\section{Animal materials}

The Committee for Animal Research, Toho University School of Medicine approved all animal procedures.

\section{Cell isolation}

Wistar rat aortae derived from the thoracic to the abdominal region were washed with phosphate buffered saline (PBS). All connective tissue, adventitia and adipose tissues were removed, and then the aortae were incubated in PBS containing $0.25 \%$ trypsin (Invitrogen Corp., Carlsbad, CA, USA), 0.1\% collagenase type I (Invitrogen Corp., Carlsbad, CA, USA), and $0.02 \%$ glucose for 20 minutes at $37^{\circ} \mathrm{C}$. Endothelial cells were removed, the aorta was minced, and vascular smooth muscle cells (VSMCs) were isolated from the suspension by repetitive pipetting. Cells in the supernatant were transferred into tubes containing $20 \mathrm{ml}$ of Iscove's Modified Dulbecco's Medium (IMDM: Invitrogen Corp., Carlsbad, CA, USA) containing $10 \%$ fetal bovine serum (FBS: Invitrogen Corp., Carlsbad, CA, USA), penicillin G (100 U/ml), and streptomycin $(100 \mu \mathrm{g} / \mathrm{ml})$. After centrifugation at $600 \mathrm{~g}$ for 6 minutes at room temperature, the cell pellet was resuspended in the medium described above and cultured for 3 passages at $37^{\circ} \mathrm{C}$ in $5 \% \mathrm{CO}_{2} / 95 \%$ air as VSMCs.

\section{Biograft}

The 3-layer $(1 \mathrm{~mm})$ thick biodegradable poly-Llactide- $\varepsilon$-caprolactone copolymer P(LA/CL) matrix consisted of a knitted fibrous poly-L-lactide (PLLA) sheet inserted between a spongy $50 \%$-caprolactone $/ 50 \%$ L-lactide copolymer (Fig. 1).

A biograft was produced by VSMCs seeded on the biodegradable $\mathrm{P}(\mathrm{LA} / \mathrm{CL})$ material.

\section{Cell culture study onto $P$ (LA/CL)}

Figure 2 shows the culture conditions of the following groups:

A) Static culture $(\mathrm{n}=11)$ : cell culture in and on the material for 4 weeks;

B) Dynamic culture $(\mathrm{n}=12)$ : cell culture in and on the patch in spinner flasks for 4 weeks;

C) $0 \mathrm{~h}$ pre-seeding $(\mathrm{n}=12)$ : static cell culture in and on the material for $0 \mathrm{~h}$ before dynamic culture for 4 weeks;

D) $24 \mathrm{~h}$ pre-seeding $(\mathrm{n}=5)$ : static cell culture in and on the material for $24 \mathrm{~h}$ before dynamic culture for 4 weeks;

E) 1 week pre-seeding $(\mathrm{n}=12)$ : static cell culture in and on the material for 1 week before dynamic culture for 3 weeks.

Static culture: stationary cell culture after seeding on the material (cell density: $0.5 \times 10^{6} / 100 \mathrm{~mm}^{3}$ ).

Dynamic culture: cell culture in spinner flasks at 60 rpm (cell density: $\left.0.5 \times 10^{6} / 100 \mathrm{~mm}^{3}\right)($ Fig. 3).

Pre-seeding: Static cell seeding and culture before dynamic culture.

\section{Evaluation}

The cells in the P (LA/CL) matrix were counted immediately after seeding, immediately after pre-seeding, and at 1, 2, 3, and 4 weeks after culture. However, because the cells attached to the biodegradable material could not be counted, we extracted the DNA from these cells to determine the numbers. ${ }^{6}$ )

Cell proliferation was histologically evaluated by staining with hematoxylin-eosin (HE), Elastica Van Gieson (EVG), Elastica Masson Trichrome (EMT) and smooth muscle actin ( $\alpha$-SMA).

\section{Statistical analysis}

All data are expressed as means \pm SD and were statistically analyzed using repeated measures ANOVA and the Bonferroni/Dunn test. 


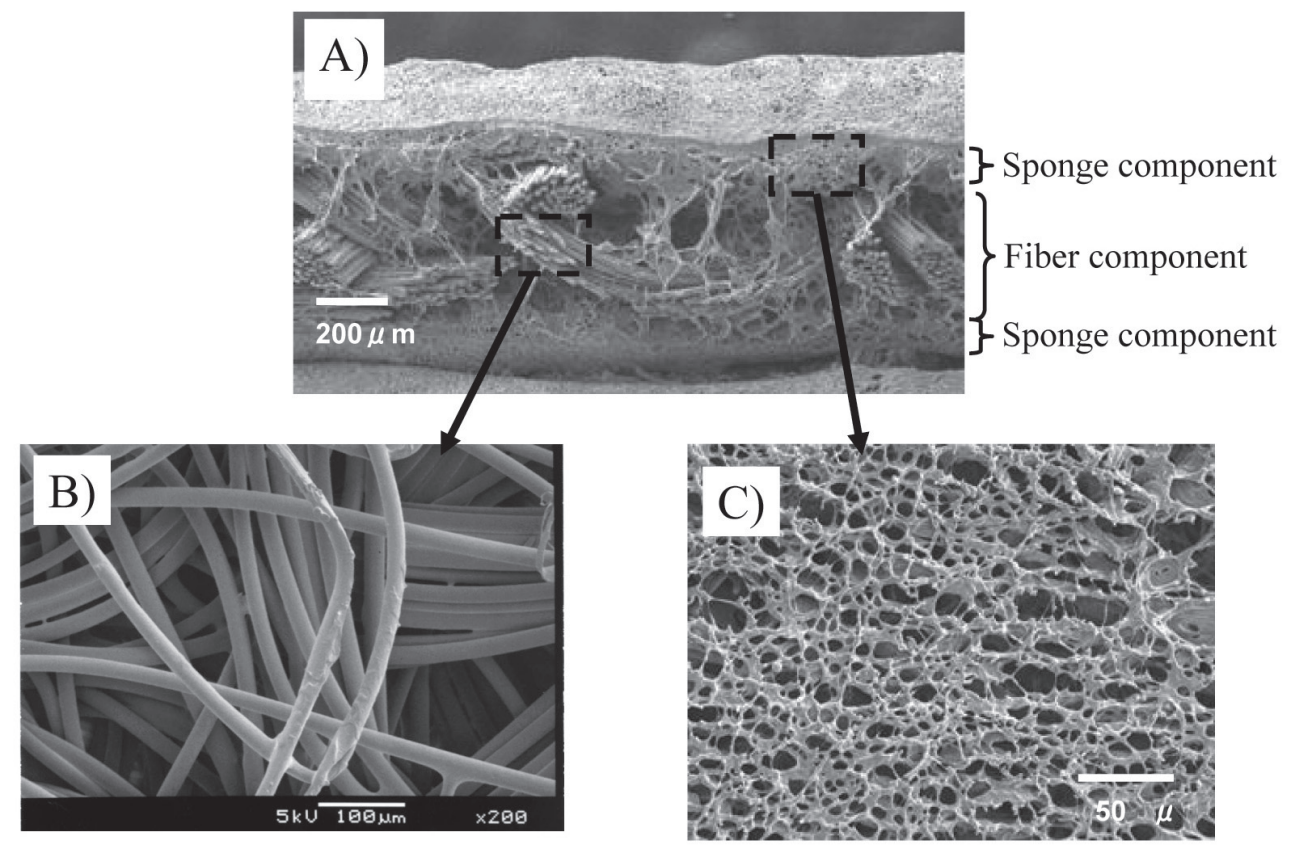

Fig. 1 Biodegradable P (LA/CL).

A) Combined structure (3-layer construction $\times 80$ )

B) Fiber component (slow absorption part $\times 200$ )

C) Sponge component (Fast absorption part $\times 500)$

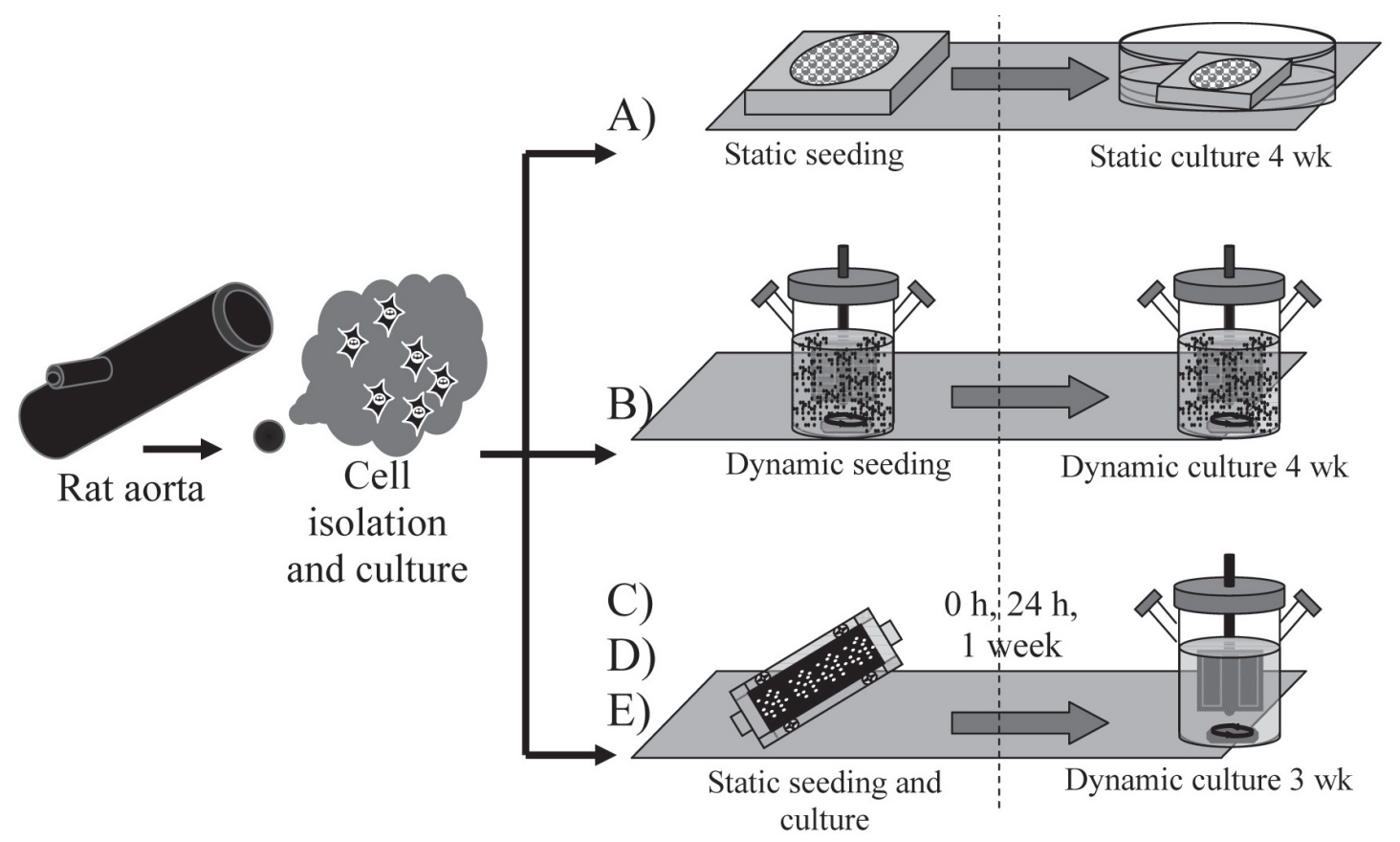

Fig. 2 Cell culture protocol.

A) Static culture; B) dynamic culture; C), D), E) pre-seeding for $0 \mathrm{~h}, 24 \mathrm{~h}$ and 1 week. 
A)

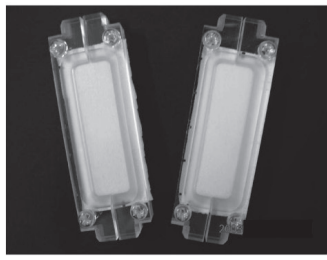

B)

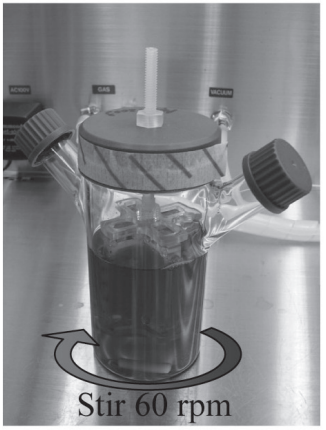

C)

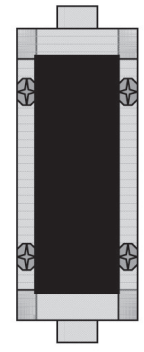

D)

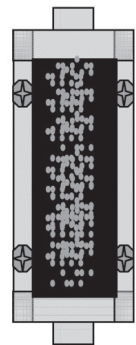

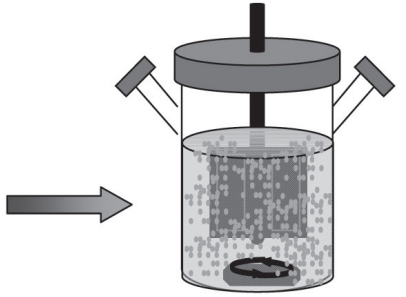

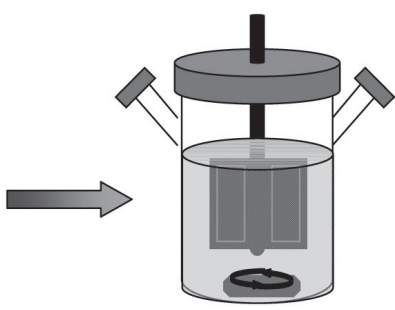

Fig. 3 Dynamic cell culture system.

A) P(LA/CL) patch with holder; B) Spinner flask; C) Pre-seeding (-); D) Pre-seeding (+)

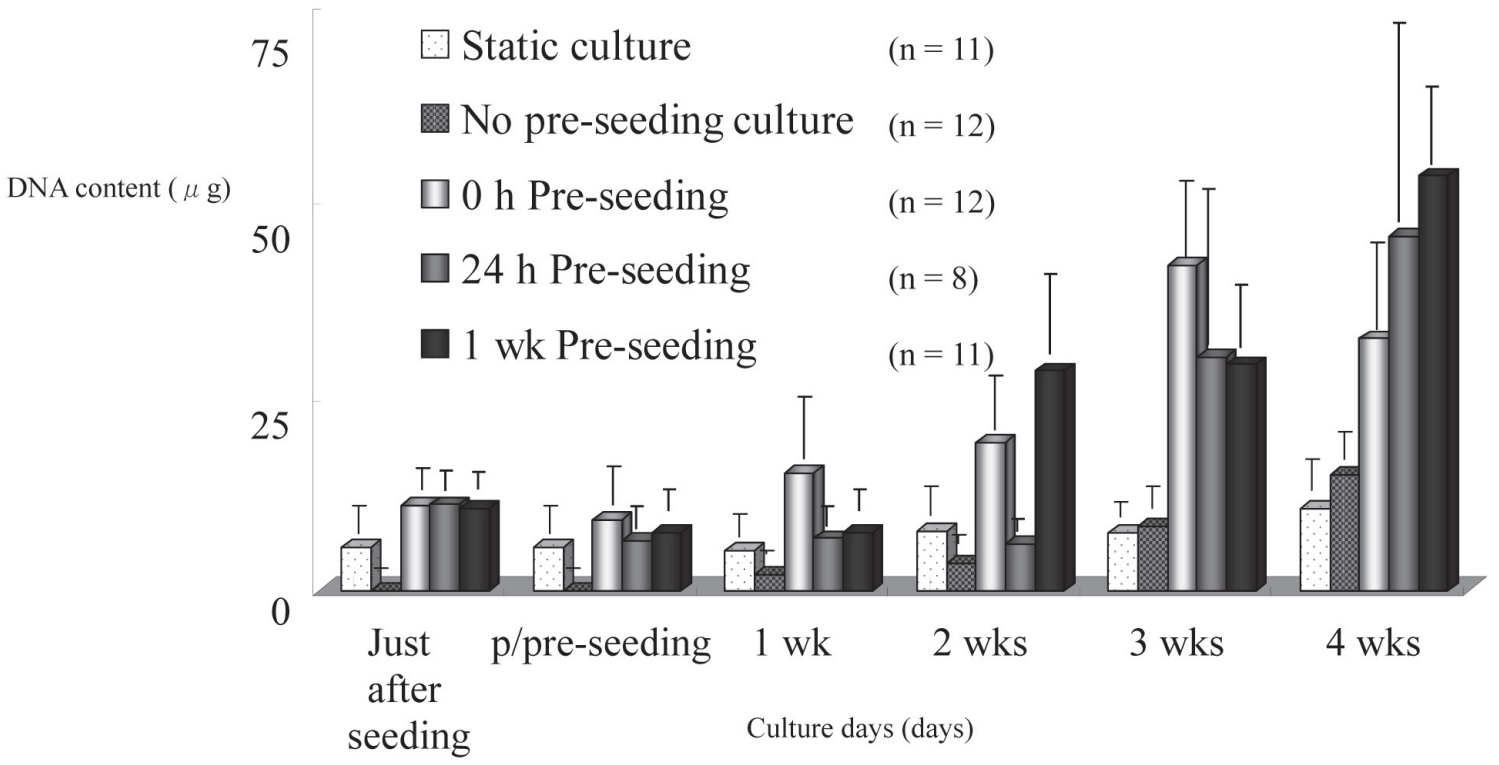

Fig. 4 Cell culture studies on P (LA/CL).

\section{Results}

The cultured cells at passage 3 were stained positive with a monoclonal antibody against $\alpha$-SMA (SMA, Sigma-Aldrich Co., St. Louis, MO, USA) and with the avidin-biotin complex (ABC) method. The estimated average ratio (\%) of positive cells was $70.3 \%$ at passage 3 . We confirmed that the cultured cells were smooth muscle cells as described. ${ }^{6}$

The average DNA contents of the cells cultured in the biodegradable materials at 1 and 4 weeks after culture were $5.08 \pm 2.6$ and $10.45 \pm 3.6$ in the static culture group, $1.98 \pm 0.4$ and $14.76 \pm 3.7$ in the dynamic culture group, $15.0 \pm 8.2$ and $32.1 \pm 11.4$ in the $0 \mathrm{~h}$ pre-seeding group, $6.63 \pm 2.6$ and $45.3 \pm 25.6$ in the $24 \mathrm{~h}$ pre-seeding group and $7.41 \pm 3.0$ and $52.94 \pm 10.4 \mu \mathrm{g} / 100 \mathrm{~mm}^{3}$ in the 1 week 


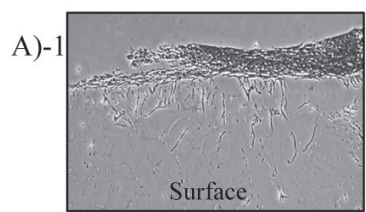

C)-1
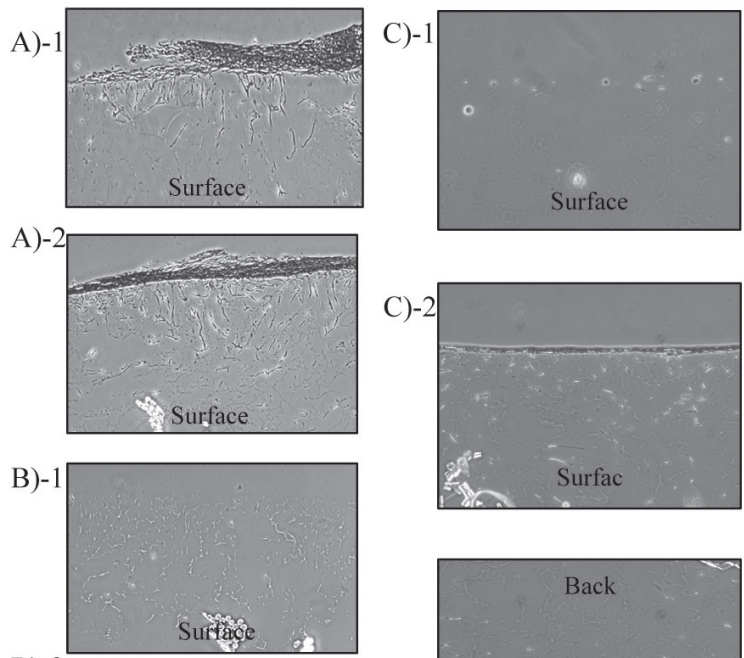

B)-

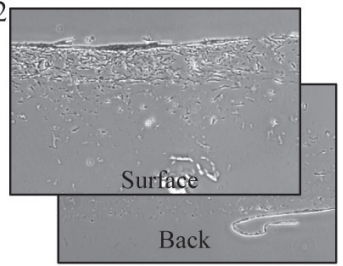

C)-2
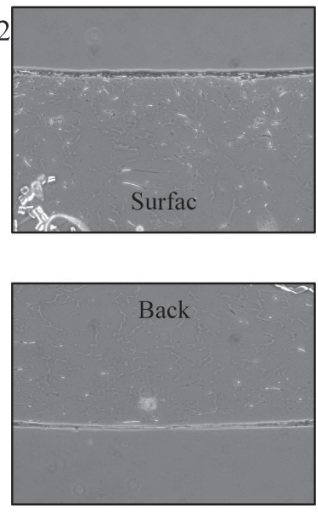
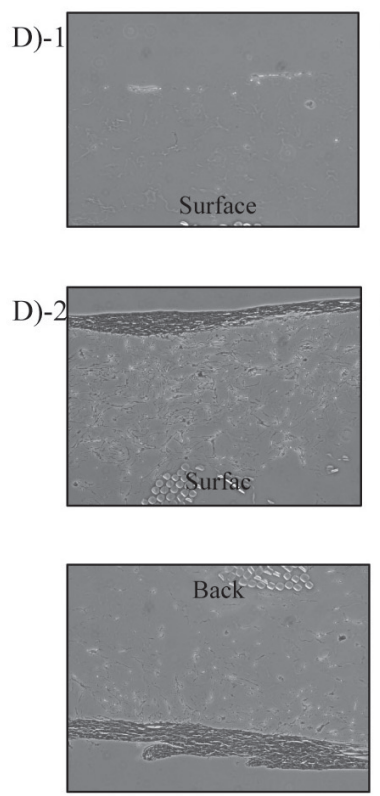
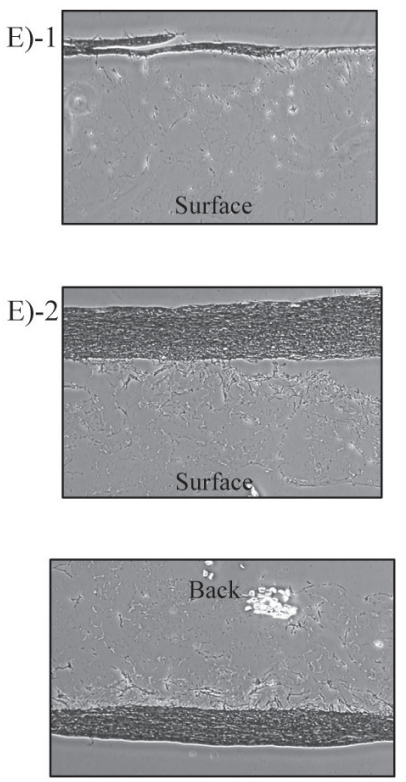

Fig. 5 Histology of cells cultured on biodegradable material (H.E. stain $\times 40$ ).

A) Static culture; B) Dynamic culture; C) $0 \mathrm{~h}$ pre-seeding; D) $24 \mathrm{~h}$ pre-seeding; E) 1week pre-seeding;

$-1: 1$ wk after culture; $-2: 4$ wk after culture

pre-seeding group, respectively (Fig. 4).

Histological study HE staining showed that cells proliferated for 4 weeks both on and in the biodegradable material. Although the cells could proliferate just at surface of the material in the static culture group (Fig. 5A), the cells also grew at the surface, and back and inside the material in the dynamic culture groups (Fig. 5B-5E). Furthermore, the number of cells on and in the biodegradable material was increased by dynamic culture with pre-seeding. Considerably more numbers of cells proliferated in the biodegradable material at $24 \mathrm{~h}$ in the preseeding, than in the other groups (Fig. 5D).

Most of the cells that proliferated on the biodegradable material were not identified as fibroblasts by EVG and EMT staining, and many of them were $\alpha$-SMA-positive.

\section{Discussion}

Artificial materials used in cardiovascular surgery as conduits or patches created from Dacron (polyethylene terephthalate), Gore-Tex (polytetrafluoroethylene), glutaraldehyde-treated bovine pericardium, or glutaraldehydetreated homografts have historically been invariable, and do not grow, are not contractile, and are thrombogenic and pose a risk of infection. These materials have the added disadvantage of persisting inside the body after implantation. All of these problems could be solved by using a biodegradable material. However, biodegradable materials require durability for clinical applications. The biodegradable material used in the present study is sufficient to construct a durable biograft harboring seeded muscle cells.

Tissue engineering confers far more benefits to the damaged heart than cell transplantation. Furthermore, a biograft constructed of optimal autologous cells and an optimal biodegradable material would avoid immunological rejection. We proposed that a durable biograft could be efficiently prepared by dynamic culture after preseeding. ${ }^{9)}$

Vascular smooth muscle cells (VSMCs) would be a target for repair of the damaged heart by tissue engineering because these cells are highly proliferative, should induce angiogenesis in the graft, ${ }^{10)}$ and release extra cellular matrix.

We therefore postulate that a bioengineered autologous VSMC graft could serve as an ideal biograft.

The VSMCs could attach and proliferate on and in $\mathrm{P}$ (LA/CL) under both static and dynamic cell culture 
conditions for 4 weeks. Cell proliferation was much more obvious in the dynamic, than in the static group cultured on the $\mathrm{P}(\mathrm{LA} / \mathrm{CL})$ material. Pre-seeding provided a superior environment for dynamic VSMC culture.

Dynamic culture and scaffold chemistry were well known to have effects on cell proliferation, ECM releasing, and phenotype of cell regulation. Furthermore, we think that the effect of pre-seeding was able to seed the cells to the scaffold perpendicularly, and let the cells have adequate time for an opportunity to contact and attach the scaffold stably. The optimal combination between pre-seeding and dynamic culture will serve to construct an ideal biograft.

Therefore, we studied the optimal term of pre-seeding. Cells attached within the biodegradable material were prevented from proliferating because cells on the surface became overgrown in the 1 week pre-seeding group. Cell attachment and proliferation were widely scattered in the $0 \mathrm{~h}$ pre-seeding group. Although the duration of preseeding did not cause any significant differences, $24 \mathrm{~h}$ of pre-seeding was the best environment for cell attachment and proliferation on and in the biodegradable matrix.

\section{Conclusions}

An optimal durable biograft was brought about by 24 $\mathrm{h}$ of pre-seeding followed by dynamic culture on and in a biodegradable $\mathrm{P}(\mathrm{LA} / \mathrm{CL})$ material.

\section{Acknowledgments}

We are indebted to Prof. K. Koike and Associate Prof. Y. Tanaka (Faculty of pharmacology, Toho University) for valuable cooperation. We also thank Drs. Ren-Ke Li and Richard D. Weisel (Division of Cardiac Surgery at the Toronto General Hospital, ON, Canada) for technical advice, and Prof. Y. Ikada (Nara Medical University Indoor Environmental Medicine) and Mr. S. Matsuda (GUNZE Ltd. Research \& Development centre) for providing biodegradable materials. We also thank Mitsubishi Kagaku Bio-Clinical Safety Institute Ltd (MBC) for histological analysis. I thank Satomi Kawarasaki and
Keisuke Hatano for fundamental research into the dynamic cell culture protocol, Showko Nanba and Yuka Nagashima for static culture, Ayako Ota, Koji Sasaki and Hiroyuki Nawase for dynamic culture with pre-seeding.

This study was supported by a grant from the Science Research Promotion Fund of the Promotion and Mutual Aid Corporation for Private Schools of Japan.

\section{References}

1) Morishita R, Aoki M, Hashiya N, et al. Safety evaluation of clinical gene therapy using hepatocyte growth factor to treat peripheral arterial disease. Hypertension 2004; 44: 203-9.

2) Strauer BE, Brehm M, Zeus T, et al. Repair of infarcted myocardium by autologous intracoronary mononuclear bone marrow cell transplantation in humans. Circulation 2002; 106: 1913-8.

3) Menasche P, Hagege AA, Scorsin M, et al. Myoblast transplantation for heart failure. Lancet 2001; 357: 279-80.

4) Mocini D, Staibano M, Mele L, et al. Autologous bone marrow mononuclear cell transplantation in patients undergoing coronary artery bypass grafting. Am Heart J 2006; 151: 192-7.

5) Matsumura G, Hibino N, Ikada Y, et al. Successful application of tissue engineered vascular autografts: clinical experience. Biomaterial 2003; 24: 2303-8.

6) Kim BS, Putnam AJ, Kulik TJ. Optimizing seeding and culture methods to engineer smooth muscle tissue on biodegradable polymer matrices. Biotechnol Bioeng 1998; 57: 46-54.

7) Kim BS, Nikolovski J, Bonadio J, et al. Engineered smooth muscle tissues: regulating cell phenotype with the scaffold. Experimental Cell Research 1999; 251: 318-28.

8) Williams C, Wick TM. Perfusion bioreactor for small diameter tissue-engineered arteries. Tissue Eng 2004; 10: 930-41.

9) Yokomuro H, Ozawa T, Fujii T, et al. Effects on proliferation ability of vascular smooth muscle cells by dynamic cell culture-A utility of pre-seeding technique for dynamic cell culture. J Cardiol 2007; 50: 309-16.

10) Li RK, Jia ZQ, Weisel RD, et al. Survival and function of bioengineered cardiac grafts. Circulation 1999; 100: II63-9. 